INTERNATIONAL JOURNAL OF RESEARCHES IN BIOSCIENCES, AGRICULTURE AND TECHNOLOGY (C) VISHWASHANTI MULTIPURPOSE SOCIETY (Global Peace Multipurpose Society) R. No. MH-659/13(N) wWw.vmsindia.org

\title{
ISOMERIC TRANSFORMATION OF CERTAIN NEW HETROCYCLIC COMPOUNDS
}

\section{B. Jadhao}

Department of Chemistry, Dharampeth M. P. Deo Memorial Science College, Nagpur M.S. (India) drdbjadhao3@gmail.com

\begin{abstract}
:
The isomeric transformation of 2-tetra-O- acetyl - $\beta$ - D -glucopyransylamino-4- phynyl -5- aryl/alkylimino1,3,4thiadiazoline have been investigated in $5 \%$ aqueous sodium carbonate solution under two conditions. When the transformation was tried with heating duration of 60 min.,2- phenyl 3- aryl /akylimino-4-tetra-O-acetyl- $\beta$-Dglucopyranosyl-5-mercapto-1,2,4-triazolines have been isolated almost exclusively. While increasing the heating time to 6-8 h., a mixture of two products , (i) 2-phenyl-3-aryl/alkylimino 4-tetra-O-acetyl- $\beta$-D glucopyranosyl 15-hydroxy(enolic)-1,2,4-triazolines (major) and (ii) 2-phenyl-3-aryl/alkylimino 4-tetra-O-acetyl- $\beta$-Dglucopyranosyl-5-mercapto-1,2,4- triazolines (minor) have been isolated. The structural assignments have been made on the basis of certain chemical transformations and UV, IR, NMR, mass spectral analysis.
\end{abstract}

\section{Introduction:}

Nucleosides having $\beta$-D glucopyranosyl group at the ring nitrogen of cyclic system or exo-cyclic nitrogen or exocyclic nitrogen of heterocyclic system or cyclic compounds have varied applications in paper, textile and food industries. Some of these compounds have application in medicinal chemistry as a diuretic agent, analgesics, antibiotics, bacteriostatic \& antituberculotic reagents and antitumor agents.

As a part of wider program me of research of synthesis of 2- $\beta-D-$ glucopyranosylimino-4-H/Phenyl-5-

aryl/alkylimino-1,3,4-thiadiazolidines have been carried out by the interaction of 1-tetra-O-acetyl $\beta$-D-glucopyranosyl-4-

$\mathrm{H} /$ Phenylthiosemicarbazide and alkyl/aryl isothiocyanates followed by deacetylation with methanolic ammonia solution.

The resultant product seems to be of pharmaceutical important and during the synthesis of it, all required care was taken to use minimum organic solvents. Simple and one/two step reactions are taken into consideration for all chemical transformation.

Experimental: Typical isomeric transformations at two different heating durations are as stated below.

(a )Reaction for heating duration of $\mathbf{3 0} \mathbf{~ m i n . : ~}$ In a $100 \mathrm{ml}$. round bottom flask $50 \mathrm{ml}$. of $5 \%$ aqueous sodium carbonate solution was taken and to it $3.5 \mathrm{~g}$. of 2 -tetra-O- acetyl- $\beta-\mathrm{D}$ - glucopyranosylamino-4-phynyl-5-phenylimino1,3,4-thiadiazolidines was added, colour of reaction mixture turned pale yellow, after words the reaction mixture was refluxed over boiling water bath for $30 \mathrm{~min}$. The reaction mixture was cooled and filtered. To the filtrate aqueous dil. Hydrochloric acid solution was added to neutralize the alkaline solution, when a solid was obtained. It was filtered and washed thoroughly with distilled water and then dried (2.8g.) solid was isolated, m. p. $1190 \mathrm{C}$

(b) Reaction for heating duration of 6-8 hours: When $5 \mathrm{~g}$. of 2 - tetra -O- acetyl - $\beta$-Dglucopyranosylamino-1,3,4-thiadiazoline was dissolved in $5 \%$ aqueous sodium carbonate solution $(65 \mathrm{ml})$. The reaction mixture turned slightly brownish in colour. It was stirred thoroughly and refluxed directly over a gentle flame for about 6-8 h. during defluxion slow elimination of hydrogen sulphide was observed. After heating, the reaction mixture was cooled and filtered. The resultant alkaline solution was neutralized by adding dil. Hydrochloric acid solution, when product was precipitated out. It was filtered and washed thoroughly with distilled water and then dried, a white solid (3.2 g) was isolated m. p. 126-132 0 C. This product was found to be a mixture of two products. These two products have been separated by column chromatography (silica gel- aqueous ethanol 1: 5).(i) m. p.125 0C (major) (ii) m. p. 119 OC 


\section{EXPERIMENTAL; SYNTHESIS OF INTERMEDIATES}

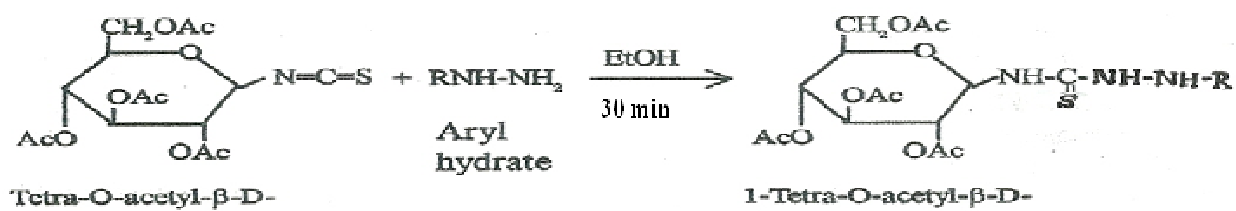

Tetra-O-acetyl- $\beta-D$

1-Tetra-O-aceryl- $\beta-D$ -

glucopyranosy

Cyclo condensition

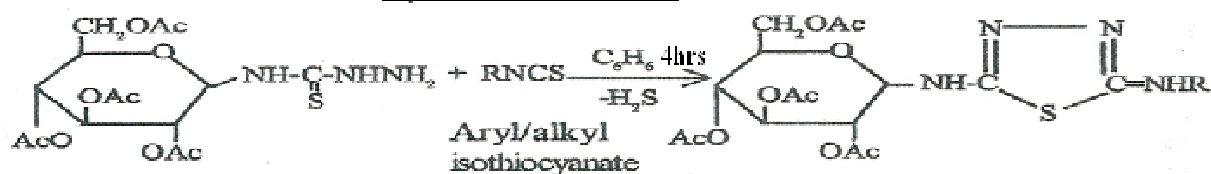

1-Tetra- $O$-acetyi- $\beta$ - $D-$

2-Tetra-Q-acetyl- $\beta-D$

glucopyranosylamino-5-aryi-

thioscrinicusbuzidite

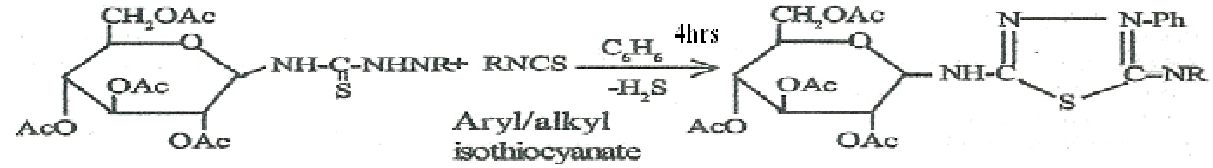

1 -Tetra-O-acetyl- $\beta-D-$

g 1 u $<$ o p y ran o 8 y 1

2-Tetra-O-acetyl- $\beta-D$ -

gluoopyranosylamino-4.

thiosemicarbazide

phenyl-5-aryl/aiky

The overall reaction may be represented as follows:-<smiles>O=[W]Nc1nn(-c2ccccc2)c(=[W])s1</smiles>

III

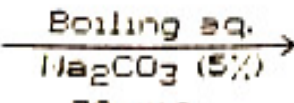
$30 \mathrm{~mm}$.

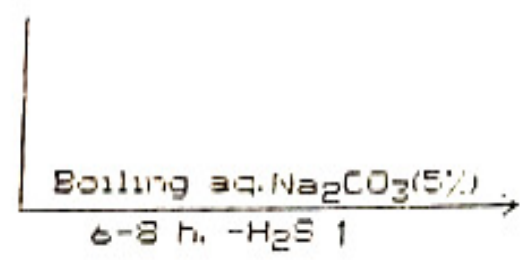<smiles>[R]N=C1N([GeH2])N=C(S)N(P)N1[GaH2]</smiles>

ionly foroduct)

I

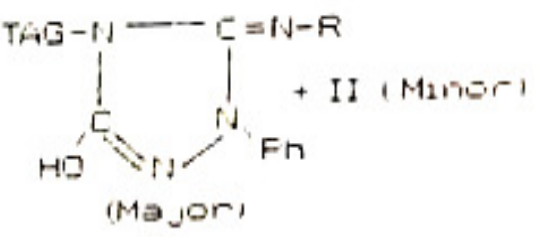

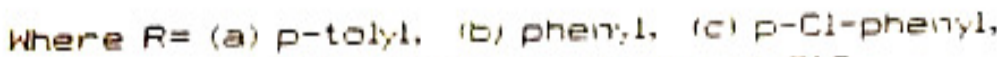

(d) ter-t-butid, (e) nethit, if, TÁs

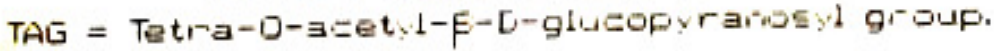

Fr, = Frienyl group. 
Table -1

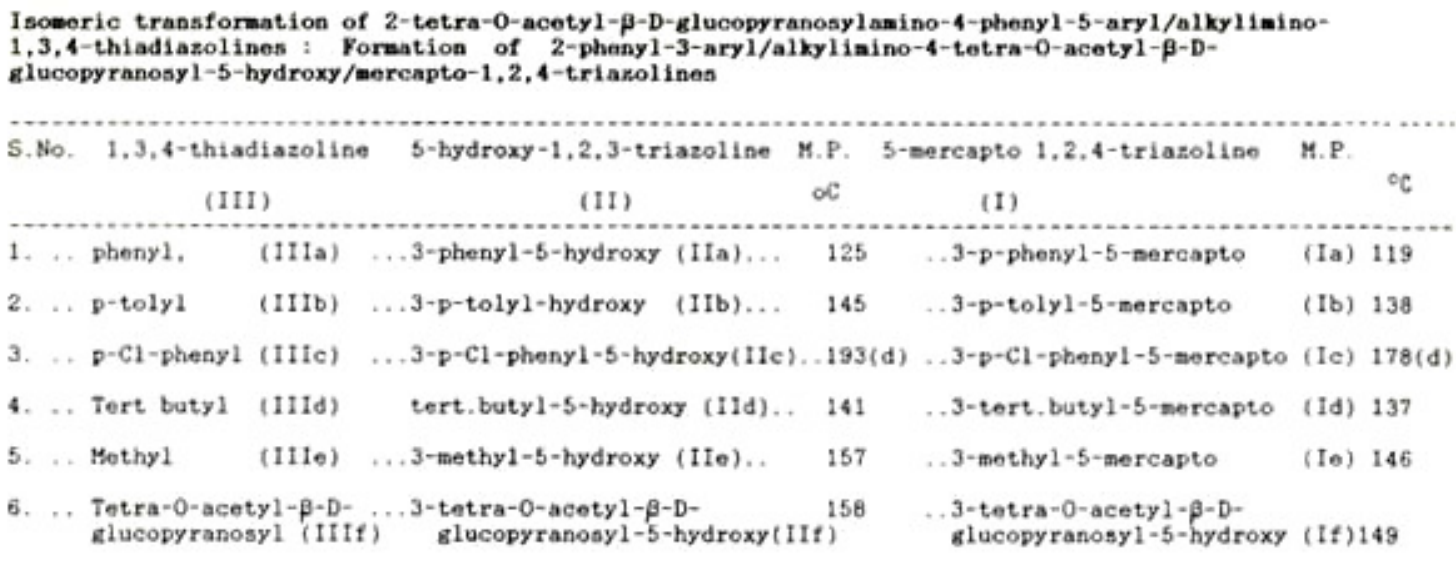

\section{TABLE 3: SPECTRAL DATA OF ACETYLATED PRODUCT:}

\begin{tabular}{|c|c|c|c|}
\hline Compound no. & IR band at & NMR Sign่nal at & Mass \\
\hline $3-a$ & $\begin{array}{c}3320(\mathrm{NH}) \text { Stretching } \\
1750(\mathrm{C}=0) \text { Stretching } \\
1640(\mathrm{C}=\mathrm{N}) \text { Stretching } \\
680(\mathrm{C}-\mathrm{S}) \text { Stretching } \\
900(\beta \text {-isomeric form of } \\
\text { pyranosyl ring) }\end{array}$ & $\begin{array}{l}\text { 8, } 2.2 \text { ppm (acetyl) } \\
\text { 8.8.I ppm (NH) } \\
\text { 8,4.I3 to } 4.21 \text { Ppm } \beta \text { - } \\
\text { D-Glucopyranosyl }\end{array}$ & $\begin{array}{c}\text { Parent peak at } \\
\mathrm{M} / \mathrm{e} 522 \\
\text { Other prominent } \\
\text { peaks also } \\
\text { observed. }\end{array}$ \\
\hline 3-b & $\begin{array}{c}3320(\mathrm{M})(\mathrm{NH}) \text { Stretching } \\
1750(\mathrm{~S})(\mathrm{C}=\mathrm{O}) \text { Stretching } \\
1520(\mathrm{M})(\mathrm{C}=\mathrm{N}) \text { Stretching } \\
800(\mathrm{~S})(\mathrm{C}-\mathrm{S}) \text { Stretching } \\
899(\mathrm{M})(\beta \text { Glucoside } \\
\text { anomeric ring) }\end{array}$ & $\begin{array}{l}\text { 8,2.66 ppm ( } \mathrm{NH}) \\
8,2.00 \text { ppm (methyl) } \\
8,7.00 \text { to } 7.16 \text { ppm ( } \beta \\
\text { aromatic configeration) }\end{array}$ & - \\
\hline
\end{tabular}

\section{TABLE-4:SPECTRAL DATA OF DEACETYLATED PRODUCT}

\begin{tabular}{|c|c|c|c|}
\hline $\begin{array}{l}\text { Compound } \\
\text { no. }\end{array}$ & IR band at & NMR Signals at & Mass \\
\hline \multirow[t]{5}{*}{ 1-a } & $3420(\mathrm{~m}) \mathrm{O}-\mathrm{H}$ Sretching & \multirow{5}{*}{$\begin{array}{c}\text { 6,2.23 ppm } \mathrm{N}-\mathrm{H} \\
8,4.84 \text { ppm } \mathrm{O}-\mathrm{H} \\
\text { 8,7.14to } 7.80 \text { ppm } \\
\text { Aromatic proton } \\
\text { 8, 3.68 to } \\
4.20 \text { ppm } \beta- \\
\text { anomeric } \\
\text { cofiguration }\end{array}$} & \multirow{5}{*}{$\begin{array}{c}\text { Product } \\
\text { Shows } \\
\text { Parent } \\
\text { Peak at } \\
\text { M/e } 354 \\
\text { However } \\
\text { other } \\
\text { important } \\
\text { fragment } \\
\text { peak also } \\
\text { observed. }\end{array}$} \\
\hline & $3330(\mathrm{~m}) \mathrm{N}-\mathrm{H}$ Sretching & & \\
\hline & $1510(w) C=N$ Sretching & & \\
\hline & 600 (s) C-S Sretching & & \\
\hline & $\begin{array}{l}891 \text { (w) Glucoside } \\
\text { deformation } \\
\text { ( } \beta \text {-anomer) }\end{array}$ & & \\
\hline
\end{tabular}




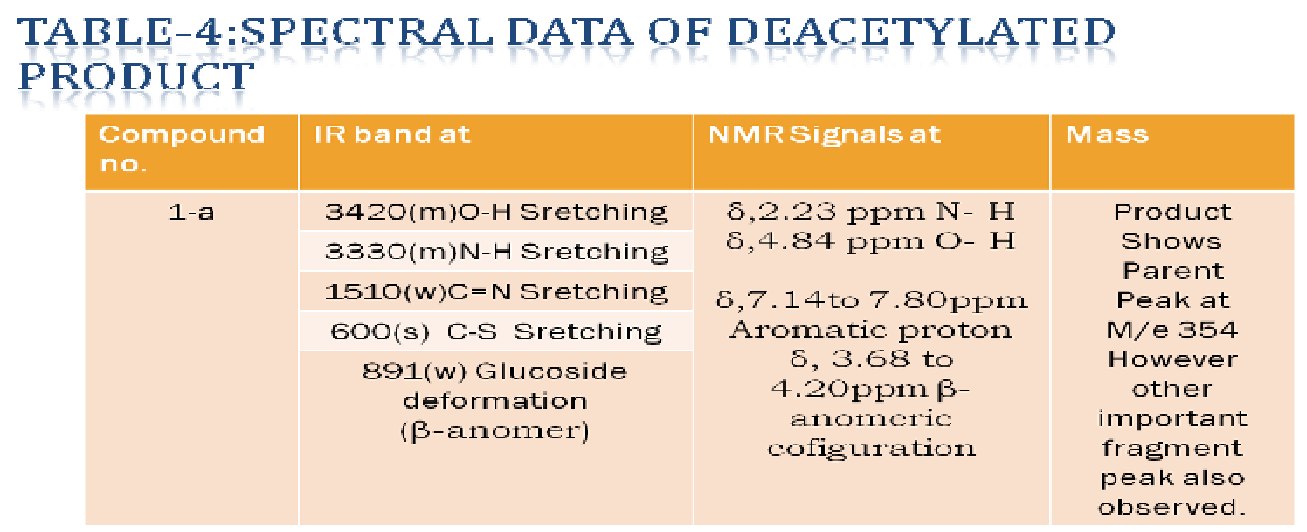

\section{Result and Discussion:}

The product with m. p. 119 OC was assigned the structure 2-phenyl-3- phenyl imino-4- tetra - O - acetyl- $\beta$-D-glucopyranosyl5 -- $\beta$-D-glucopyranosyl ring mercapto-1,2,4trizoline and the product with m. p. $1250 \mathrm{C}$ did not contain sulphur.It contain four nitrogen, out of which three nitrogen were the part of 1,2,4trizoline ring and one present as imino nitrogen while oxygen was present as an enolic form. The product charred with conc. Sulphuric acid and showed positive Mollisch, sTest, optically active. The UV spectrum of the product was recorded and showed lambda max at $270 \mathrm{~nm}$ in alcohol. The IR spectrum of the product clearly indicated the presence of $\mathrm{v}-\mathrm{OH}, \mathrm{v}--\mathrm{NH}, \mathrm{v}-\mathrm{C}=\mathrm{N}, \mathrm{v}-\mathrm{C}=\mathrm{O}$ bands in addition to usual bands of - $\beta$-Dglucopyranosyl ring. The NMR specrum displayed signals due yo aromatic nucleus, $\mathrm{OH}$, and $\mathrm{NH}$. It also showed signals due to protons of - $\beta$-D-glucopyranosyl ring, mass spectrum of the product show molecular ion peak at 523 , besides this other important fragment peaks at 463,331, 229, 169, 109, were clearly located.

On the basis of the above fact the product with m. p $1250 \mathrm{C}$ was assigned the structure 2phenyl- 3- phenylimino-4- tetra-O-acetyl- $\beta$-Dglucopyranosyl -5-hydroxy (enolic)-1,2,4triazoline (IIa) major.

\section{Conclusion:}

One can draw a conclusion From the observed fact that Isomeric transformations of certain glucosylated heterocyclic compounds can be done with $5 \%$ aqueous sodium carbonate solution by two heating durations that is 30 min. and 6-8 h. These products then tried for deacetylation. in presence of methanolic ammonia at $10^{\circ} \mathrm{C}$. Isomeric transformation and blocking and reopening of desired functional group was carried out successfully. Whatever position of carbon atom in glucosyl ring was blocked in the form of acetyl group was then made available as hydroxyl group for further reactions, that is Phosphorylation of synthetic Nucleosides to convert it in to corresponding synthetic Nucleotides.

\section{References:}

1. B.N. Berad and M. G. Paranjpe:Annual convention of chemists, Culcutta,Oct.15,1984 Paper no. ORG (4).

2. S. H. Pine:" Organic Chemistry"MvGraw-Hill, New York, International Ed. 5 th Ed.(1979).

3. I.B.Bedekar,A.R. Joshi and M. G. Paranjpe: J. Indian Chemical Soc., 58, 1016 (1981).

4. N. B. Colthup,L. H. Daly and S. E. Wimberley: Introduction to Infrared and Raman Spectroscopy" Academic Press NewYark,(1964).

5. R.M. Silverstein, G.C. Bassler and T.C. Morril: Spectroscopic Identification of Organic Compounds" 4th Ed.,JohnWileyand Sons., INC, NNewYork(1981).

6. S. A. Barker, E. J. Bourne, r. Stephensand D.H. Whiffen: J. Chem. Soc., 3468 (1954).

7. Margareta Avram and GH. D. Mateescu: "Infrared Spectroscopy by Application in Organic Chemistry" John Wileyand sons.,INC,NewYork (1970).

8. J.R. Dyer: Applications of Absorption Spectroscopy of Organic Compounds", Prentice$\mathrm{Hal}$

9. Shenyou Nie Wei Li And Biao Yu: Prroduct Chemistry of Bio organic \&Natural Product Chem. J.Am.Chem. Soc. 2014 Mar 19:136(11); 4157-60 doi: 1021/ju501460J. Epub. 2014 Mar 11 